\title{
History-based Explanatory Framework for Procreative Behaviour of Aboriginal People of Canada
}

\author{
Anatole Romaniuk \\ Adjunct Professor of Sociology \\ and Population Research Laboratory \\ University of Alberta \\ Edmonton, Canada, T6G 2H4 \\ anromaniuk@rogers.com
}

\begin{abstract}
The transition from traditional high to modern low fertility is in the forefront of empirical and theoretical investigations in contemporary aboriginal demography. The challenging question therein remains why its fertility has started to decline a century or so after the rest of Canada, and why it continues to trail the latter by a considerable lag. The objective of this paper is to present a history-based explanatory framework of the childbearing behaviour of Canadian aboriginal peoples, as it has evolved over time from the very first contact with Europeans to our day. Turning to existing theories for possible elucidation of these idiosyncrasies, we find that while accounting for certain aspects, they leave others unexplained. History provides a more satisfying explanation when we cast an eye not on the "abstract" population, "ideal-type" or what we today like to call "model", but on real population, or family thereof, in its spatio-temporal context. The "between-two-cultures" paradigm presented here, based on ethnocentricity and dependency, could be seen as a an explanatory paradigm of competing forces on the Canadian aboriginals: on the one hand, those pushing toward modern norms of childbearing; and on the other, traditional values and structures, as shattered as they are, with their pro-natalist ideologies resisting normative changes.
\end{abstract}

Key Words: aboriginal populations, fertility, demographic transition 
Anatole Romaniuk

\section{Résumé}

La transition de la fécondité de son niveau traditionnel élevé à son niveau moderne faible est au centre même des préoccupations théoriques et empiriques de la démographie contemporaine des peoples autochtones du Canada. La question que se posent les démographes est de savoir pourquoi la fécondité autochtone a commencé son déclin avec plus ou moins un siècle de retard sur l'ensemble de la population canadienne et pourquoi elle accuse encore toujours un retard sur cette dernière. Le but de cet article est de présenter un cadre exploratoire, basé sur l'histoire, des comportements procréateurs des peoples autochtones dès les premiers contacts avec les européens jusqu'à nos jours. Les théories existantes, si elles permettent d'élucider certains aspects des idéocyncracies de la fécondité autochtone, laissent d'autres sans explication. L'histoire fournit, à notre avis, une meilleur explication de particularités des comportements procréateurs des autochtones, si nous faisons abstraction des populations, conçues comme «populations-types » ou ce que de nos jours on a l'habitude de qualifier de «modèles», pour regarder de face les populations réelles dans leur contexte spatio-temporel. Le paradigme, présenté ici, «entreles deux-cultures» avec ses deux axes — ethnocentrisme et dépendance peut être vu comme un paradigme de confrontation entre, d'une part, les forces de modernité, poussant les populations autochtones à adapter les normes modernes de procréation et, d'autre part, les valeurs culturelles et les structures sociales ancestrales, aussi dégradées qu'elles le soient, mais qui tendent néanmoins à préserver les idéologies pro-natalistes et qui comme telles résistent aux changements normatifs en matière de procréation.

Mots-clés: populations autochtones, fécondité, transition démographique,

\section{Introduction}

The objective of this paper is to present a history-based explanatory framework of the childbearing behaviour of Canadian aboriginal peoples, as it has evolved over time from the very first contact with Europeans to our day. To this end we will first sketch out the historical itinerary of fertility, focusing for the sake of brevity on its most revealing periods. In so doing we will not fail to be impressed by the singularity of the shape the aboriginal fertility curve takes in its historical perspective. The transition from traditional high to modern low 
fertility is in the forefront of empirical and theoretical investigations in contemporary aboriginal demography. The challenging question therein remains why its fertility has started to decline a century or so after the rest of Canada, and why it continues to trail the latter by a considerable lag. Turning to existing theories for possible elucidation of these idiosyncrasies, we find that while accounting for certain aspects, they leave others unexplained. History provides a more satisfying explanation when we cast an eye not on the "abstract" population, "ideal-type" or what we today like to call "model", but on real population, or family thereof, in its spatio-temporal context. We will then proceed to outline our history-based explanatory framework. The underlying rationale being that, the encounter of aboriginal peoples with European civilizations produced, along with the unique political status they occupy among all other minorities, typical objective and subjective relations with Canadian society at large, and lasting power structures and perceptions - all of which influence directly and indirectly their procreative attitudes and behaviours. While still only tentative, the proposed framework opens, in our opinion, fruitful avenues for exploring the possibility of a more satisfactory, though still historybased, theoretical paradigm of aboriginal peoples' childbearing behaviour in Canada, and, by extension, of aboriginal peoples in other countries with similar colonial and governance histories.

\section{Fertility Trends: A Synoptic View}

When looked upon historically aboriginal fertility (see Figure 1) went through a variety of distinct stages in terms of its levels. Drawing on the inferences derived from their living conditions and prevailing customs, we may characterize the fertility regime of traditional, pre- and early contact era, typical of aboriginal people, as being that of sub-optimality. Then with the conquest, as a consequence to the spread of the epidemics imported from Europe, came demographic collapse. The demographic recovery followed with the relapse of epidemics, and the fertility too probably recovered some of its traditional features. Moreover the early modernization brought an increase in natural fertility in the post-war years and up to the mid-sixties. Then the fertility rate took a nose-dive, followed by a slow downward and even an apparent arrest in the downward trend. Now aboriginal fertility is somewhere towards mid-way of what is called the demographic transition from the high traditional towards low modern fertility patterns. Let's have a closer look at each of the identified phases of aboriginal fertility as it has unfolded historically. 
Anatole Romaniuk

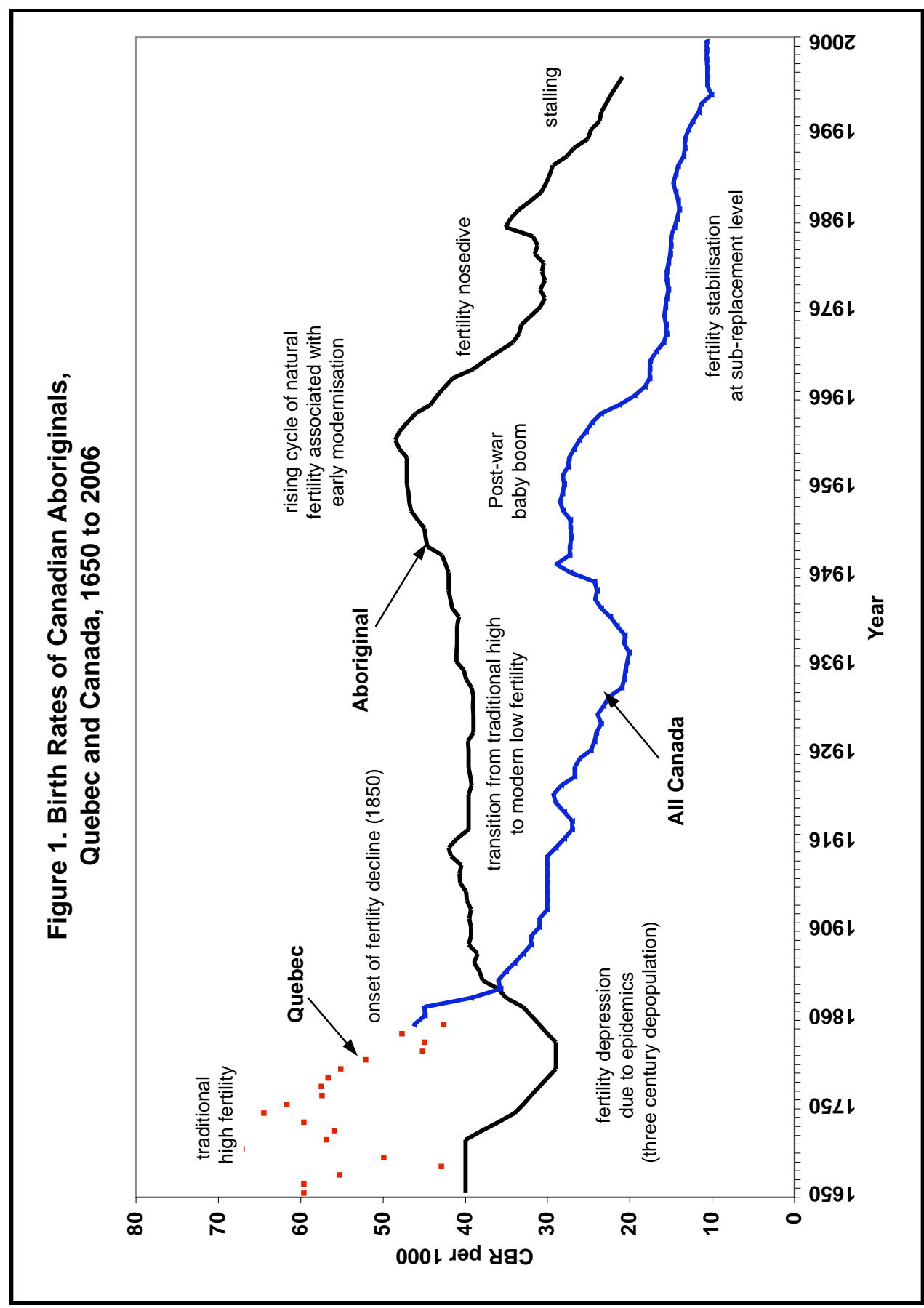

CSP 2008, 35.1: 159-186 


\section{Pre- and Early Colonization Period: Less Than Optimal Childbearing Performance}

We do not know the childbearing habits of the Indians when the Europeans first arrived. No hard-pressed explorer paid attention to such questions; no established missionaries or administrators took the trouble of carrying some kind of survey. All we have of the very early days of contact are some observations that have been documented and survived to our day on marriage customs, sexual mores, living conditions; these allow us by inferences to gain vague insight into the procreative regimes of the day. The examination of that material led us to conclude that fertility among aboriginals might not have been as high as one would expect of a pre-modern population.

Specifically, a host of factors conspired to produce a reproductive regime that can be qualified as sub-optimal. In laymen's terms this means that reproduction in those early days probably fell far short of its potential. First are ecology hardship-related factors. Malnutrition, not to speak of outright sporadic starvation, poor hygiene, and accidents due to nomadic life in a harsh, long winter habitat may have delayed conception and caused pregnant women to miscarry, abort or even commit infanticide (Belekci, 1972). Second, and foremost, due to the absence of animal milk or equivalent natural substitutes, mothers breast-fed their children over a long duration, and this in turn tended to depress fecundity and spaced pregnancies further apart. Third, a set of fertility depressing factors pertains to what may be called sexual and marital behaviours. Early reports speak of conjugal instability and sexual promiscuity among some tribes. Explorers and early pioneers were unimpressed by the prolificity of Indian families. They were struck by the small number of offspring, and the frequency of barrenness among native women.

\section{The Long Haul Demographic Collapse Brought by the European Conquest}

The introduction of new contagious diseases by European colonists resulted in an excessive mortality among Aboriginals, all the more so because of their lack of immunity (Heagerty, 1928). While we have some idea of the scale of human devastation by these epidemics (Cook, 1998; Dickason, 1992), we don't know how they may have affected the procreative behaviour; in fact no such question has been asked as far as we know. But there can be little doubt that such infections such as measles, scarlet fever, diphtheria, chicken-pox, smallpox, typhus, typhoid fever, that caused so many deaths, also caused some impairment to the reproductive organs of the individuals that eventually survived the ordeal. One may only surmise with good reason that individuals who survived may have been in too a weak state of physical health for a prolonged time that they were incapable of sexual intercourse or to conceive and carry a pregnancy to term. Moreover it is 
medically documented that certain contagious diseases such as measles may cause sterility in men and women (McFalls \& McFalls, 1984). Aside from epidemics in the wake of the European invasion and their effect on reproductive health, there were also socially disruptive influences of colonization. Rampant alcoholism was probably the chief culprit, no less destructive to family and community cohesion than to the individual himself. All we can say in conclusion with a reasonable degree of supposition is that lower fertility was a factor, albeit far less so than mortality, in the nearly three centuries depopulation of aboriginal peoples that accompanied the conquest and colonisation (Charbonneau, 1984).

\section{Demographic Recovery in the First Half of the $20^{\text {th }}$ Century}

The long haul process of depopulation of Aboriginal peoples reached its nadir at the turn of the 20th century and a slow journey towards demographic recovery began thereafter. Underlying this at first sluggish but predictable recovery is the progressive control over, and elimination of, the very same causes which were responsible for depopulation. First and foremost, the fight against the epidemics took a turn for the better. It may be posited with some confidence that as result thereof, fertility too recovered some of its traditional "normalcy". For the period up to World War II at least, and even up to 1945, the aboriginal peoples were still largely insulated from modern influences, preserved and maybe even recovered some of the pre- and early colonial features of procreative behaviours, with a birth rate of about 40 per 1,000 population.

\section{Post-War Years Rising Cycle of Natural Fertility Associated with Early Modernization}

Developments since World War II brought Canadian Indians increasingly under the influence of what may be called modernisation. Communication greatly improved, and with it, exposure to the style of life prevalent in Canadian society intensified. Indians in the North shifted increasingly from their traditional hunting and trapping occupations to modem types of employment and gave up their semi-nomadic mode of life for established permanent settlements (Dunning, 1954; Rogers, 1963). Elementary education was quasi-universal by the 1960s, and a high proportion of Indian youth went beyond that level of education. Living conditions have improved both through greater opportunities for Indians as wage earners and through more generous government welfare grants. The most notable achievements, however, have been with regard to health. Infant mortality, as high as 240 infant deaths per thousand births by rough estimates at the beginning of the century and about 200 at the outbreak of 
World War II, fell to slightly over 30 per thousand births in the late seventies (Romaniuc, 1974, 1981).

What was the demographic response in terms of childbearing performance to these modernizing trends among native populations? If one had to take the theory of demographic transition as a modus operandi of changes in procreative behaviour, one would have expected the onset of a decline in fertility as the modernization processes pressed ahead. But it did not happen until much later. In the meantime fertility went up significantly to about $46-48$ birth per 1000 population by late 1960s. Why? Well before large scale birth control sets in, and brings the fertility rate down, modernization tends to remove or weaken the fertility-inhibiting factors operating in traditional societies, and which were responsible for sub-optimal childbearing performance. It has been well documented (Romaniuc 1974, 1981) that the emergence of modern breastfeeding practices was most likely the major factor of heightened tempo of reproduction, that is shorter child-spacing among aboriginal people. Younger generations of mothers who either did not breastfeed at all or who did so for shorter periods of time were more prevalent among the younger than among the older cohorts. Two additional factors are hypothesized to have contributed to higher fecundity and hence shorter child spacing. One is the reduction in the level of pregnancy wastage due to medical progress, medical assistance during delivery and pre- and post-natal medical follow-up. The other factor seems to be a lesser incidence of prolonged separations of spouses as the Indian people shifted from a semi-nomadic to a settled society, and the means of transportation improved (Romaniuc, 2003).

\section{Transition from Traditional High to Modern Low Fertility Levels}

As spectacular as the rising fertility cycle associated with the early modernization was, it happened to be a short-lived phenomenon - it lasted just about one and half decades. Almost suddenly, without any perceived warning sign, the aboriginal people of Canada were swept into a powerful decline in the late sixties. Birth rate dropped from its high point of about 46-48 around 1965 to about 28 births per 1,000 women by 1980 . How did this happen? All one can say is that much of the period during which the fertility decline took place coincides with an acceleration of socio-economic development. To whatever indicators one turns - education, health, housing, labour force participation or income - neither the years before nor after can claim the impressive performances of the 60s and 70s. Regrettably, however, we are in no position to establish analytically meaningful linkages and mechanisms underlying the decline in fertility, against the background of these socio-economic developments. However, this much might be said at this point: this dramatic 
downturn in fertility occurred spontaneously - spontaneously in the sense that it was not brought about by large-scale family planning masterminded and directed by the government or any central agency, as might have happened in some developing countries. No grand scale family planning programme ever took place in Canada, generally or specifically targeted at aboriginal populations. To be sure, unlike populations of some developing countries, they have benefited from the various public health amenities, including some limited family planning services, available to the Canadian population in general. Furthermore, it should be recalled that the collapse of the aboriginal birth rate coincided with the contraceptive revolution - pills and IUDs in the 60s and sterilization in the $70 \mathrm{~s}$ - which took place in Canada, and which most likely "spilled over" into aboriginal communities.

\section{Stalling Fertility Decline}

A near free fall of the fertility rate from the mid-sixties to the early eighties has given way in more recent years to a marked slowdown, for a while to a halt, or even an apparent recovery, a mini baby boom, possibly an echo of the increasingly larger cohorts of women born during the rising cycle of birth rates (natural fertility referred to earlier), entering childbearing ages. Nor was it even across the social spectrum and geographical habitat. Fertility levels are observed to be lower among Métis, among southern more than northern Indian settlements, and highest among far North Inuit. Why this stalling? The question remains enigmatic. It is possible that the transformations in aboriginal society have not yet gone far enough to bring about the full cycle of demographic transition. On all the key developmental scores - female labour force participation, level of education, or average income, the aboriginal population fall short, and by a significant margin, of Canadians at large. Note that instances of such a midway slowdown or temporary lulls in fertility transition are not uncommon (Hirschman, 1986), but little light has been thrown on the underlying causes.

\section{Emergence of Fertility Differentials}

The emergence of social, economic and residential differentials in fertility is the hallmark of early transition to modernity. As with many other populations, the process of transition was not simultaneous across the social boundaries, but sequential. It started with groups in the vanguard of social change, the most educated and urbanised. Education, while delaying family formation, tends to further non-family roles (work, profession) and receptivity to modern birth control technology. Urbanisation, while promoting aspirations that are more 
work and consumption-oriented, entails a whole array of disincentives for having large families. Thus kinship support for raising children is more difficult to come by in cities than in traditional communities, and the cost of housing is higher as well. Higher incomes, earned as a result of economic growth, make the choice more meaningful between family and non-family investments (consumption of superior goods and leisure) with this choice tilting toward the latter. Quality takes precedence over quantity of children as wealth rises. Finally, for women, the taking up of wage employment poses a difficult dilemma in terms of both the 'opportunity cost' of childbearing and the incompatibility of the dual role of working and parenting. The advent of modern, highly efficient, contraceptive technology, along with greater job opportunities brought about by economic growth, has opened up alternatives to parenthood.

Table 1 exhibits the existence of fertility differentials by education and habitat that may be explained by the above stated arguments. Likewise, there are differentials in fertility by aboriginal sub-groups: the Inuit retaining the high, and the Métis the low edge in the fertility scale (see Table 2). A more detailing geography of aboriginal fertility would reveal the progression of fertility from South to North, from settlements more exposed to modern influences by the simple fact of their vicinity with urban agglomerations and the availability of wage employment opportunities, to those still largely insulated in the North (Bone, 1992).

Table 1

Total Fertility Rate by Rural-Urban Habitat and Level of Education Canada: 1981-1986

\begin{tabular}{lccccc}
\hline \multicolumn{2}{c}{ Habitat } & Education & & \\
\cline { 1 - 3 } Rural & Urban & $\begin{array}{c}\text { Less than } \\
\text { grade 9 }\end{array}$ & $\begin{array}{c}\text { Grades 9- } \\
\mathbf{1 3}\end{array}$ & $\begin{array}{c}\text { Higher than } \\
\text { grade 13 }\end{array}$ & $\begin{array}{c}\text { All } \\
\text { Indians }\end{array}$ \\
\hline 3.49 & 2.34 & 3.70 & 2.95 & 2.29 & 2.78 \\
\hline
\end{tabular}

Source: Ram, Bali, 1991. Assimilation and fertility of native Indians: Some new evidence. Paper presented to the Annual Meeting of the Canadian Population Society, June, 1991. Kingston, Ontario. 
Anatole Romaniuk

Table 2

Total Fertility Rate for Aboriginal Groups and Total Population

Canada: 1996-2001

\begin{tabular}{cccccc}
\hline $\begin{array}{c}\text { All } \\
\text { Aboriginal } \\
\text { Groups }\end{array}$ & Indians & $\begin{array}{c}\text { Registered } \\
\text { Indians }\end{array}$ & Métis & Inuit & $\begin{array}{c}\text { All } \\
\text { Canada }\end{array}$ \\
\hline 2.60 & 2.81 & 2.68 & 2.15 & 3.21 & 1.50 \\
\hline
\end{tabular}

Source: Ram, Bali, 2004 . New Estimates of Aboriginal Fertility, 1966-1971 to 19962001. Canadian Studies in Population, Vol. 31(2), pp. 179-196..

Note: The rates are estimated by the "children-own" method from children 0-4 old, from the 2001 census of population.

\section{Aboriginal and All-Canadian Fertility in Historic Perspective: an Overview}

Figure1 depicts the birth rate trends from the beginning of the European (French) colonization to our days, for all-Canadians and Aboriginals. It is a composite picture. The data are real for the whole historical span under observation for all-Canadians, with the exception that earlier periods of colonization are real for Quebec only, the latter representing the region of early colonization. For aboriginal peoples the curve represents estimated and actual birth rates from about 1900 onwards, whereas for previous periods they are inferential, as explained in the early section on less-than-optimal childbearing performance in the pre- and early colonization periods. Moreover, the curves in both cases, aboriginal and all-Canadian, are smoothed, overlooking small fluctuations to focus on grand stages in fertility evolution over time. With the above qualifications, Figure 1 is instructive of how different the two fertility histories are. The following are the significant features:

- $\quad$ Big differences in fertility between all-Canadian (French settlers at that time in history) and aboriginal populations for the early periods of colonisation;

- Deep, long lasting, fertility depression associated with the three centuries of aboriginal depopulation; 
- Whereas aboriginal fertility takes the route of slow recovery by around 1900, all of Canada fertility embarks on the steady transition from high to low fertility (as of about 1850);

- Both Aboriginals and Canadians exhibit their baby booms, though with some lag in time. However, the underlying factors are different. In the case of Canadians, it is due to the uniqueness of the historical setting the Great depression and World War after-effects and post-war prosperity, stability and optimism concomitant with the still strong traditional pro-family sentiments prevailing in the population (Romaniuc, 1994). The rising aboriginal fertility cycle was due, as explained earlier, to the relaxation of traditional inhibiting factors brought about by the early modernisation, before the onset of large scale birth limitations.

- Resumption by the Canadian population of its century-old fertility decline, stabilizing as of 1980 at about a birth rate of 10 per 1,000 or total fertility rate of 1.5 per woman. Aboriginal fertility as of the mid1960 takes a nose dive, followed by a slow down and even a stalling of the decline.

- Probably the most remarkable phenomenon is the tardiness of aboriginal people's fertility transition, by about a century as compared to that of Canada as a whole. Why so late? After all the two populations lived side-by-side for almost four centuries. Even so aboriginal fertility is far from having run its course; it is only on its midway course, with the fertility rate yet being almost twice that of Canada as a whole.

It is the latter phenomenon - the long-lasting lag in fertility transition - that has attracted the greatest attention of researchers, interested in both empirical and theoretical aspects of aboriginal fertility. Next we shall review some of the relevant theories.

\section{Theoretical Perspective}

A great deal of ground in the testing of theories against statistical data has been covered by other students (Trovato, 1987; Trovato and Burch 1980). Trovato's 1987 study, A macrosociological analysis of native Indian fertility in Canada: 1961 1971, and 1982, is particularly relevant to the question at hand. I shall confine myself to summarizing the tested theoretical thesis and hypotheses, and to presenting significant findings. 
1. The modernity thesis whereby fertility declines over time due to the emergence of the fertility-inhibiting effects of modernization;

2. The fertility-enhancing effects of modernization, whereby the traditional inhibiting factors are removed or weakened before full-scale voluntary birth limitation practices set in;

3. Characteristics-assimilation hypothesis whereby initial discrepancies among various subpopulations in the levels of fertility tend to converge as the socio-economic conditions equalize;

4. Minority status insecurity hypothesis, whereby disadvantaged minorities because of their sense of insecurity and an upward mobility ambitions lead them to consciously curtail family size as a means to achieve higher socioeconomic status;

5. Pronatalist subculture thesis, whereby ethnicity per se, due to its inherent pronatalist norms will have a positive effect on fertility even when socio-economic variables are held constant;

A multivariate macro sociological analysis of children ever born carried out by Trovato, utilizing such predictors as type of residence, ethnicity (Indians), NonIndian population (as comparative standard), age, and time period as independent variables, provided strong support for hypotheses (1), (2), (3) and (5), but no support for hypothesis (4), that is the minority insecurity. Trovato summarizes his findings in the following way: "In substantive terms the findings suggest that while modernization generally implies long-term declines in native Indian fertility, their above average levels of reproduction are likely to persist for a considerable length of time, mostly as function of the pronatalist subculture of natives and the discontinuous nature of modernization process" (1987:463).

The question may be asked, why the minority insecurity thesis fails the test in the aboriginal case when it seems to work when tested against other minorities. For an answer we may have to turn to history. It might well be that minority insecurity is a two edge proposition, depending ultimately, as Trovato and Burch (1980) point out in another paper. For immigrants and their descendents, minority status insecurity leads to fertility limitation, as a means to attain upward mobility. On the other hand, the Aboriginals' sense of insecurity associated with their marginal status in society may have the opposite effect, to raise their fertility. 
Let's tread along the theoretical line a little bit further by focussing on the theory of demographic transition. It is par excellence the general quasi universal conceptual framework within which the demographic processes in modern time are explored and explained. In its earlier formulation (Notestein, 1945; Landry, 1949), basically the conceptualisation of the western European demographic experience, emphasis was on decline in mortality, greater child survival, as the key determinant of fertility decline. As populations in many other parts of the world embarked on the course of demographic transition and the demographic experiences expended in scope, many other variables - cultural, social, economic and ideational, alongside child survival - were brought into the gambit of causality. Urbanisation and more so education are elevated to key factors in the downward reassessment of childbearing norms in developing countries. Recognition of the twin engines of the modernisation process technology (productivity, mass consumerism and contraceptive technology) and ideational mind set (secularism, rationalism and individualism) gave rise to many new conceptual derivatives and vocabulary, some borrowed from other social science disciplines. We speak about childbearing calculus and decision making in such terms as opportunity cost, parenting and work incompatibility, workforce feminisation versus 'gains from trade', intergenerational wealth transfer, parenthood as a deliberate act of choice and not as a matter of faith and biology, self-fulfilment over more gregarious values like family and kinship. By no means are these kinds of rhetorical expressions, or catch words, without much substance. In actuality they are conceptualisations of rational, psychological and at times emotional complexes, that intervene in the couples' childbearing calculus. They serve as intermediaries between decision making regarding childbearing, on the one hand, and fundamental economic, social, cultural and technological forces operating in society, on the other. It would take us too far to further elaborate on these concepts. It suffices to say that these entire conceptual wherewithals, combined with empirical field experience, earlier in western, and presently in emerging nations, have made the theory of demographic transition a powerful analytical tool of the demographic processes under the impact of modernity across the world.

Yet with all its remarkable achievements, the theory of demographic transition, by its very focus on transition from traditional high to modern low vital levels, is wanting in other important respects. The pre-transitional demographic processes are left to population historians and anthropologists. In passing it might be said the transition theory has little to say on the post-transitional stage, demographic maturity, with its inherent sub-replacement fertility. More to the point, it has paid little attention to the modernisation fertility-enhancing factors which have been empirically documented (Romaniuk, 1974; Romaniuc, 1981; Trovato, 1987). Nor does it fully recognise the power of cultural resistance to modernity - what Trovato calls the cultural natalist residual. More generally, 
when we observe real world experiences with transition to low fertility, we find an amassing multitude of 'transitions' - country, region, civilisation and époque-related - as to their morphology and causation ( $\mathrm{Ni}$ Bhrolcháin and Dyson, 2007). This is why to be really comprehended and explained each individual 'transition' ought to be studied in its own historical context. This is no less true for the Canadian aboriginal fertility - its rather peculiar historical journey, as visualised in Figure 1, and more specifically the late advent of its transition. And it is on this variation of the theme, the historical setting, that we will embark in the next portion of this paper.

\section{Structure of a History-Based Explanatory Framework}

If one takes a broad view of the aboriginal peoples' history since the conquest onward, ethnocentrism and dependency emerge as two dominant dimensions of their relationship to the Canadian State and the dominant large society. As illustrated in Figure 2, the history-based explanatory framework postulates that the combination of these two basic features with their derivatives, identified in the respective individual modules thereof has resulted in a duality of aboriginal identity, a 'man of two cultures', or an 'in-between society', with its typical procreative behaviours. A brief description of the main features of the proposed framework is provided below, first along the ethnocentric axis, then along the dependency axis.

\section{Native Ethnocentrism and its Demographic (Fertility) Ramifications: Political and Cultural Identity}

From the earlier days of colonisation to the present, aboriginal peoples have struggled and succeeded to a considerable degree in preserving their cultural heritage, ethnic identity, and in some limits their political autonomy as well. Aside from the inner, self-directed aspiration for recognition, circumstantial factors, flowing from their history, have also fostered a distinct identity. Of paramount importance in this regard, it seems, are reservations, with their limited self-government and territorial integrity. Notwithstanding other rather unwelcome aspects of the segregated nature of reserves, they may have helped aboriginal people to survive as a distinct entity. The insistence on the need to preserve traditional modes of life (hunting, trapping, and fishing) in their historical territories, while sometimes serving as a bargaining chip for land claims, seems to underscore their profound will to preserve traditional life styles and longing to reconnect with the past. Attempts to abolish the Indian Act and dismantle the reservation system have met with widespread opposition of Indians at large and their political leadership, and have been viewed as a 
Figure 2

History-based Explanatory Framework for Procreative Behaviours of Aboriginal People

\section{FERTILITY EXPLANATORY FRAMEWORK UNDER CONDITIONS OF THE ENCOUNTER OF WESTERN- ABORIGINAL CIVILISATIONS}

\section{ETHNOCENTRISM}

POLITICAL\&CULTURAL IDENTITY

- $\quad$ Struggle for recognition as unifying factor

- $\quad$ Special political status

- Reserves as territorial entity

- Discrimination (self-imposed)

SOCIO-CULTURAL FEATURES

- Cosmocentric (holistic) rather than homocentric outlook

- Group rather than individual interest

- Solidarity and co-operation rather than competition

PRONATALIST CULTURE

- $\quad$ Survivalist strategies of pre-modern society reinforced by the threat of annihilation or assimilation

- Support for family values

- Aversion towards anti-natalist measures

\section{DEPENDENCY}

\section{POLITICAL SOCIAL, ECONOMIC \& ECONOMIC DEPENDENCY}

- Coercive control, paternalism

- Resocialisation, assimilation

- Discrimination (imposed)

- Interaction-consultation

- Pervasive welfare system

\section{CULTURE OF POVERTY \&} SOCIAL DISORGANISATION

- Alcoholism

- Family breakdown

- Delinquency

- Suicide \& homicide

\section{MODERNISATION}

- Economic development (from subsistence to mercantile, to capitalist and to welfare economy)

- Other modernity features (education, urbanisation, female wage employment)

\section{"PERSON BETWEEN TWO WORLDS"}

\section{PROCREATIVE BEHAVIOURS}


disguised assimilation plot by the federal government (Gibbins and Ponting, 1986) .

Significant in this regard were recent constitutional debates and particularly the earlier controversies surrounding the 1969 White Paper. Indian leadership vigorously opposed it for they sensed this would pave the way to legislation that would emphasise individual rights and de-emphasise their collective ethnic survival. Recent claims for self-government are the latest, vivid manifestations of their longstanding struggle for recognition. Traditional structures and values are, according to some observers, reinforced with the greater assertion lately of aboriginal culture, political militancy, and protective legislative measures.

Such are some of the self-generated manifestations of aboriginal ethnocentrism and of the legal statutory provisions that tend to set aboriginal peoples apart in the Canadian ethnic mosaic. In addition there are repelling forces in dominant society that have contributed to this process. As Gibbons and Ponting note, "A large part of the responsibility for the failure of assimilation, must be laid at the feet of the broader Canadian society, for the obstacles posed by societal discrimination were immense. Government policy tried to induce Indians into a mainstream that was unwilling to receive them" (1986: 27).

\section{Socio-Cultural Features}

Socio-cultural features and mind-sets also positions aboriginal peoples apart from the mainstream society. As some scholars have argued (see Frideres, 2004), aboriginal peoples have a holistic and cosmo-centric, rather than Western homo-centric, view of the universe. The emphasis is on group interests rather than on individual or self-interests, on co-operation rather than competition, present rather than future, extended family rather than immediate family.

How much of these sentiments, aspirations and views of the world are actually "internalised" by individuals and couples in their childbearing decision making remains debatable. It could be plausibly argued, however, that if co-operation rather than competition is indeed society's organisational principle, then the spirit of 'social capillarity', the process by which parents moved by the desire to boost their children in the social ladder have fewer offspring (Dumont, 1990) may not be embraced by aboriginal people. 


\section{Survivalist Strategies: Pronatalist Culture}

Trovato (1978) argues that native Indian sub-culture still embraces strong pronatalist norms as a "survival strategy". Many of the social norms and values that have taken hold by the fiat of the evolutionary process of adaptation, and which have sustained a high fertility in the past, are still present in aboriginal communities in various degrees. The threat faced from the European invasion, annihilation or assimilation, may have reinforced the survival strategy. The concept of survival strategy in relation to childbearing, however, requires clarification. What does it really mean?

Does it mean that individuals have internalised these collective sentiments of insecurity and reacted accordingly in the matter of procreation? One doubts this to be the case. No individual or couple - even in the most nationalistic and expansionist minded nations, nor those under outside threat - will have children for the sake of defending their community, or acquiring some superiority for their country. People are usually guided by two principles in making decisions about childbearing, that of rationality and that of normativity. In the first instance individuals, as rational beings, are making choices in the matter of procreation so as to maximise their own and their family's well-being. In the second instance, they will adhere to the established values and traditions in their communities and proceed accordingly in the matters of childbearing. Although the two principles operate in both modern and traditional societies, their relative importance may vary. Rationality may be more prevalent in the modern, individualistic society whereas normativity is generally the guiding principle in traditional communities, and it may still be in force in aboriginal communities.

What Trovato probably meant by the survivalist strategy is not to be understood as individuals' decisions to have children for the sake of community survival, but as a set of collectively fostered values, rules and opinions that ultimately lead to having more children or to opposing external influences which tend to undermine pro-family standards. A few examples may serve to illustrate the point. Adoption outside the group into a non-aboriginal family is often actively resisted by the aboriginal community. The social stigma of illegitimacy, never too strong in many tribes, is even less now. Although, admittedly widespread, birth control - contraception and particularly abortion - was met with public disapproval (Nolte, 1982), and still is today. At the height of the wave of sterilisation practices that swept Canada in the 1970's, aboriginal newspapers routinely denounced these practises in aboriginal communities, with the outcry of ethnic "genocide" (For example, see "Illegal Sterilisation," Toronto Native Times, February 1978). These are some of the manifestations of what may be 
called the pro-natalist subculture. Even such things as moving mothers from the far-North to southern hospitals for child delivery are denounced by some as infringement of aboriginal traditions (O'Neil \& Kaufert, 1990). Marriage, partly displaced by common-law arrangements, remains a widely adhered to norm in aboriginal communities. Public opinion and pressures may have indeed acted as impediments in a diffused way for small family norms to permeate aboriginal society.

Prevailing social and economic conditions can also contribute to and sustain a pro-family and pro-natalist subculture among aboriginal people. Much of what may be labelled "pro-natalist" or "pro-family" attitudes may also derive from self-interest. Children still remain an asset to their parents, as they count on them for support in their old age. More notable in the remote rural areas, the concern for old age security is also manifest among poorly integrated urban dwellers who continue to maintain close links with their kin in the communities of origin. No less an asset to their parents are children who serve as helpers in the still prevalent traditional, household-centred economy. And this is one way the insecurity can be the factor enhancing rather than depressing the propensity of childbearing.

So much about the reproductive dimensions of the native ethnocentrism. I shall now turn to the other key axis of the paradigm: the 'dependency' conditions.

\section{Dependency and Its Demographic (Fertility) Ramifications: Political Dependency}

Aboriginal people find themselves in a state of political, social, and economic dependency vis-à-vis the large dominant society. The anthropological literature makes a great deal of the pervasive 'paternalism' and 'dependency' of aboriginal people on government agents in the conduct of public and even private affairs. "Outside authority figures have taken over the role of leaders, or attempted to do so, thus inhibiting the development of local Indian leadership" (Rogers, 1963:71). Or as another writer argued, referring to the American experience but applicable to the Canadian as well: "The near monopoly on power and initiative held by the federal government, and its immediate agents, when coupled with the absence of geographic mobility, leaves few avenues of vertical mobility open to members of the Indian society" (Zentner, 1972:223). This dependency has developed over time, from direct coercive control to much milder forms of control including various integrative and consultative processes that increasingly define relationships between Aboriginals and Canadian governments (Ponting, 1986; Boldt, 1993; Frideres, 2004). Changes for the better, in the sense of the emancipation of aboriginal leadership, have taken 
place more recently. It remains however that various traits of paternalism have to some degree survived to this day. Some level of dependency will most likely be maintained even under the self-government rule - the professed policy goal of the Federal Government.

Political dependence has consequences for childbearing, not directly, but by fostering economic dependence and its related conditions, such as the pervasive welfare system, the culture of poverty and the weakening of the internal cohesion of aboriginal communities.

\section{Economic Dependence}

In spite of widespread improvements in living conditions, and many individual success stories, poverty is still pervasive in aboriginal communities. It is more than just the material indigence per se. The challenge of poverty resides in what anthropologists refer to as a culture of poverty, as a state of mind with all its attendants - fatalism, apathy and inertia — and this has not completely lost its meaning even today. The heavy dependency of individuals, their families and even entire communities on government grants and subsidies has resulted in welfare becoming a way of life for many (Zentner, 1972). Unlike advanced societies in which the welfare state is the hallmark of affluence and a factor in fertility decline, the welfare system prevailing in aboriginal society is associated with poverty, and its perpetuation unwittingly by the very welfare state may have a stalling effect on adoption of modern procreative norms.

This is all the more so since the welfare benefits are, to some extent, determined by the size of the family. Those familiar with the situation claim that welfare has at least something to do with the increase in the number of unwed mothers and common-law unions, as unmarried mothers may draw higher welfare benefits than those legally married. Thus the welfare system in aboriginal society may be regarded as a pro-natalist factor, both in the negative and positive sense.

Dependency on government, in addition to its direct potential influence on procreative behaviour, has also an effect on kinship, according to Kunitz (1981). His study of the Navajos and other Indian populations in the United States led him to argue that the "pattern of economic non-development supported by the provision of unearned income and services has encouraged the persistence of kin networks which provide various forms of mutual support to the members and serve to redistribute income when the sources are multiple and unstable" (Kunitz, 1981:182). Stated differently, the availability of steady jobs promotes independent nuclear households whereas unstable employment fosters dependence upon a variety of sources of income and continuing reciprocity 
among kin for the redistribution of income. The offshoot of this development is, one would expect, a family context conducive to a more conservative attitude in the matter of procreation.

\section{Social Disorganisation}

There is little doubt that many aboriginal communities suffer from the ills of social disintegration, as evidenced by high rates of alcoholism, delinquency, violence, homicide and suicide. The incidences of these social anomies have been so widely observed and reported by so many students of aboriginal lives that there is hardly need to quote any particular source. Though the incidence of marriage breakdowns, common law unions and illegitimacy were traditionally rather high, at least in some aboriginal tribes, they have reached startling proportions in recent years and may be symptomatic of the weakening of the social control and kinship network.

The single most powerful agent of social disintegration is believed to be alcohol. This in itself is an interesting case of how a foreign agent brought into a society can spell great trouble. It is well known that alcoholic beverages were unknown to aboriginal peoples, but once introduced by Europeans, their consumption reached epidemic proportions in some communities; it almost became a part of a new culture, part of the "dream culture" that aboriginal peoples traditionally experienced. The devastating effect of alcohol consumption on the individuals themselves, their families and communities has been dramatized in a well crafted book, under the evocative title, "A Poison Stronger than Love - the Destruction of an Ojibwa Community” by Anastasia Shkilnyk (1985).

How then does the social disintegration affect reproductive behaviour? There is no simple answer to the question. On the one hand, there is no doubt that weakening of social control over sexual morality, marital instability, and specifically sexual promiscuity facilitate the spread of AIDS and sterilitycausing venereal diseases which have a depressing effect on fertility. On the other hand, they may cause a state of mind that is prone to carelessness, individual irresponsibility, child neglect, indifference, if not outright reluctance to adopt norms of prudential behaviour in matters of procreation, as well as safe methods of birth control. 
History-based Explanatory Framework for Procreative Behaviour

of Aboriginal People of Canada

\section{Modernisation}

It can be argued as to where modernisation really belongs - under the dependency or ethnocentrism axis - or it can claim a separate spot in our history-based explanatory framework. For simplification I decided to place it along the dependency axis, one argument being that modernisation is in many ways triggered, channelled and sustained by the dominant society. Irrespective of its position in the structure of our model, the question as to how such developmental factors associated with modernisation as education, urbanisation, and female employment can affect fertility, has already been dealt with in our discussion of fertility differentials and demographic transition. One may add here the "spill-over" effect from the dominant majority to the aboriginal minority. Here I have in mind the "spill-over" effects of events, which by their very unique occurrence go beyond the general framework of steady socioeconomic development. Thus, to give some examples, one may suspect post-war prosperity and the introduction of welfare measures, such as family allowances, may have had an upward effect on aboriginal fertility during the post-war years, beyond the already discussed fertility-enhancing effects of early modernisation. On the other hand, the explanation of the collapse of the aboriginal birth rate that followed may be found partly in the advent of the contraceptive revolution (i.e. pills and IUD in the 1960's and sterilisation in the 1970's) which spilled over rapidly into aboriginal communities. But again, unless more about the spread of birth control among aboriginal peoples is known, we are left to conjecture.

An even more puzzling question is the recent stalling in fertility decline. Little comfort can be derived from the fact that it coincides with the economic stagnation in the early 1980 's, as evidenced by a number of indicators brought up in this author's earlier papers (Romaniuc, 1987, 2000). The messages that these indicators send are actually contradictory. Thus the deterioration of employment conditions in the logic of business cycle economics would suggest a downward effect on marriage and childbearing. Yet it is the stalling of fertility decline that has been witnessed. An argument could be made that socioeconomic development may not yet have reached the critical threshold necessary to sustain the declining path of fertility. Appealing as the concept may be, it remains a rather rhetorical concept, void of substance unless a clear relationship between fertility level and what that critical threshold is, or supposed to be, can be theoretically rationalised and statistically established. This, however, is not the case to the best of my knowledge. So we are left wondering, what exactly happened to explain the stalling of fertility decline in the two recent decades, after a period of hasty decline. Maybe after all, culture and social anthropology are more relevant than economics to the understanding 
of the recent trends in procreative behaviour. Aboriginal communities may still harbour a great deal of what Trovato calls natalist residual.

\section{Individual-Between-Two-Cultures}

The dialectic along the two key axes of the arguments - ethnocentricity and dependency - merges to produce an aboriginal person, whom we may call "person-between-two-worlds". Borrowed from anthropological literature (Spady, 1982), the term is well suited as a metaphor of our own vision of the aboriginal person and his or her society as they have evolved over time under the impact of the encounter with western civilisation. Resulting from this encounter is a society wrestling with the tensions between self-preservation as a cultural and political entity, and the forces of assimilation into mainstream society. It is widely recognised, and many anthropologists have argued, that Canadian aboriginal communities suffer not only from the syndrome of dependency upon the dominant majority, from relative isolation and underdevelopment, but also are bearing the mark of duality of their identity, of an inbetween society. As "a person-of-two-cultures", the Indian is relentlessly trying to breach two relatively diverse value systems, according to Nagler (1972). These features of Indian society, while sometimes over-stated, are no doubt present even today.

The modernisation process which grew in intensity and pace since World War II is, undoubtedly, the potent factor in the development of the "between-twocultures" society. Under the impact of modernisation processes that unfold spontaneously through imitation and diffusion of modern social values and life styles, on the one hand, and through deliberate government's interference by way of legislation and administration, on the other, the traditional value system and social structures have been altered to the point of rendering aboriginal communities impotent to exercise effective control over their members. Aboriginal societies are marred, as it was already stressed, with a multitude of social anomies. Without adding any more to dominant society's guilt complex, it can be argued that some of the deliberate actions, even if well-intended, may have ultimately had a deleterious impact on the individual, family and public morality. The outlawing of Indian ceremonies, the replacement of traditional leaders, residential schools are cases in point. They may have contributed to the kind of culturally "split-personality" and the aboriginal society's dual identity, a kind of syncretism, cultural hybridisation. Yet they resisted full assimilation.

The future of aboriginal peoples cannot be predicted with any confidence. But some qualified statements can be made. Aboriginal peoples, as "between-twoworlds-societies" are in a tenuous situation. It is unlikely to resist the pressure of 
the forces that brought fertility in Canada, as in all modernising worlds, to its lowest ebbs, mostly to sub-replacement levels. The worst scenario would be the collapse of aboriginal fertility, and this could happen if the disintegration of the native society, with its value system, takes turns towards the worse, while "western values" are not fully internalised. In either case, a fertility descending to sub-replacement level would spell dire consequences for the aboriginal peoples as cultural and political entities in Canada. Unlike Canada at large, aboriginal peoples cannot rely on immigration to replenish their depleting human resources. As I wrote some years back, "Aboriginal populations will be dwarfed in relation to the ever-growing Canadian population (on account in the latter case of ever-growing immigration and also of loss of its historical identity) and in the long run will be marginalised to the point of becoming irrelevant as a political force" (Romaniuc, 2000:129).

\section{Concluding Comments}

The "between-two-cultures" paradigm presented here, based on ethnocentricity and dependency, while still wanting in many respects, could be seen as a rough cut explanatory paradigm of competing forces: on the one hand, those pushing toward modern norms of childbearing; and on the other, traditional values and structures, as shattered as they are, with their pro-natalist ideologies resisting normative changes. On balance, these factors have tended to hold back the process of decline in fertility among aboriginal Canadians. The history-based explanatory framework may not be restrictive to Canadian aboriginals alone. In fact, it may fit a broader collection of aboriginal peoples worldwide, such as aboriginal minorities across the Southern Americas (Chackiel and Peyser, 1993) and even more distant indigenous groups as those of Siberia (Bobrick, 1992, Forsyth, 1992), Australia (Jones, 1965; Grey, 1990; Taylor, 1997) and New Zealand (Pool, 1991). Time and again, comparative analyses have found striking similarities among these geographically diverse populations, as they had to meet the challenges associated with the encounter of more dominant civilizations.

The proposed history-based explanatory framework is a tentative one, and is open to improvements as more knowledge is gained from evolving research, both theoretical and empirical, on the procreative behaviours of aboriginal peoples in Canada. Specifically, the major task ahead can be subsumed in the following three steps:

- First, a more rigorous conceptualisation is needed of the individual modules of the proposed explanatory framework (and other potentially relevant ones) as well as in the establishment of the logical cause-effect 
Anatole Romaniuk

links between them and childbearing, its normative and behavioural indicators.

- Second, expend and update statistical testing of the type carried out by Trovato to reveal variations in time, but not only just macro, but also micro statistical analysis using individual data from micro public use sample tapes, available since 1971.

- Third, while submitting to the conventional methods of statistical testing macro and micro data, the richness of anthropological literature, observation-based qualitative data should be put to a greater use in exploring the aboriginal procreative behaviours and their correlates.

\section{References:}

Balikci, Asen .1972. "Female Infanticide on the Arctic Coast", In Mark Nagle (ed.) Perspectives on the North American Indian, Toronto: McClelland and Steward. Pp. 176-189.

Barsh, Russell Lawrence. 1994. Canada's Aboriginal Peoples: Social Integration or Disintegration, Canadian Journal of Native Studies Vol. XIV, No 1.

Bobrick, Benson. 1992. East of the Sun: The Epic Conquest and Tragic History of Siberia. New York: Henry Holt and Company.

Boldt, Menno. 1993. Surviving as Indians: The Challenge of SelfGovernment. Toronto: University of Toronto Press.

Bone, Robert M. 1992. The Geography of the Canadian North - Issues and Challenges. Toronto: Oxford University Press

Cassidy Frank, 1993. Surviving as Indians: The Challenge of SelfGovernment. Toronto: University of Toronto Press.

Chackiel Juan and Peyser Alexia. 1993. Indigenous Population from Latin America National Censuses, Paper presented at the Population Conference, International Union for Scientific Study of Population (IUSSP), Montreal. 
History-based Explanatory Framework for Procreative Behaviour

of Aboriginal People of Canada

Charbonneau, Hubert .1984. Trois siècles de dépopulation amérindienne, in Louise Normandeau et Victor Piché (eds.) Les populations

amérindiennes et Inuit du Canada, Montreal: Les Presses de 1'

Université de Montréal. Pp. 28-48.

Cook, Noble David. 1998. Born to Die, Disease and New World Conquest, 1492-1650. Cambridge: University Press.

Diamond, J. 1932. The Indians of Canada. Ottawa: National Museum of Canada, Bulletin 65.

Dickason, Olive Patricia. 1992. Canada's First Nations, A history of Founding Peoples from Earliest Times. Toronto: McClelland and Stewart Inc.

Dumont, Arsene. 1990 (1890). Dépopulation et Civilisation, Paris:Economica.

Forsyth James. 1992. A History of Peoples of Siberia, Russia's North Asian Colonies, 1581-1990. Cambridge University Press.

Frideres, S. James. 2004. Native Peoples in Canada - Contemporary Conflict. Scarborough: Prentice-Hall Canada.

Dunning, R. 1954. Social and Economic Change among the Northern Ojibwe. Toronto:University Toronto Press.

Gibbons, Roger and Rick, J. Ponting 1986. Arduous Journey - Canadian Indians and Decolonization. J. Rick Ponting (ed.). Toronto: McClelland and Steward.Grey, Alan. 1990. A Matter of Life and Death:

Contemporary Aboriginal Mortality, Canberra: Aboriginal Study Press.

Heagerty, John, J. 1928. Four Centuries of Medical History in Canada. Vol. I .Toronto: Macmillan.

Jenness, Diamond .1977. The Indians of Canada. Toronto: University of Toronto Press.

Kroeber, A. L. 1939. Cultural and Natural Area of Native America. Berkeley: University of California Press.

Kunitz, Stephen J. 1990. Public Policy and Mortality among Indigenous Populations of North America and Australasia, Population and Development Review 6(4): 647-672. 
Anatole Romaniuk

Landry, A. 1949. Traité de démographie. Paris: Payot.

Notestein, F.W. 1945. Population - the Long View. In T.W. Schultz (ed.) Food in the World, pp. 36-57. Chicago: University of Chicago Press.

McFalls, A. Joseph \& Marguerite Harvey McFalls. 1984. Disease and Fertility. New York: Academic Press.

Nagler, Mark, 1972, "Minority Values and Economic Achievement: The Case of the North American Indian", in Nagler Mark (ed.), Perspectives on the North American Indians, McClelland and Stewart Limited, Toronto/Montreal.

Nielsen Marianne O. and Robert A. Silverman. 1996. Native Americans, Crime, and Justice. Westview Press.

Nolte, J. 1982. 'Family planning needs of native people in Canada'. An unpublished background paper prepared for Planning Parenthood Federation of Canada, Ottawa.

Norris, Mary Jane. 1995. "Projections of Aboriginal Populations in Canada, 1991-2016: Trends and Issues," Towards the XXIst Century: Emerging Socio-demographic Trend and Policy Issues in Canada, pp. 251-263. Ottawa: Federation of Canadian Demographers.

Pool, Ian .1991. Te Iwi Maori: New Zealand Population Past, Present and Projected. Auckland, NZ: Auckland University Press.

O'Neil, John \& Patricia A. Kaufert. 1990. “The Politics of Obstetric Care: The Inuit Experience", in W. Penn Handwerker (ed.), Birth and Power, Social Change and the Politics of Reproduction, Westview Press.

Ram Bali. 2004. "New Estimates of Aboriginal Fertility, 1966-1971 to 19962001”, Canadian Studies of Population 31 (2), 2004, pp. 179-196.

Ram, Bali. 1991. Assimilation and fertility of native Indians: some new evidence. Paper resented to the Annual Meeting of the Canadian Population Society, June 1991, Kingston.

Rogers, E. S. 1963. "Changing Settlements Patterns of the Cree-Ojebwae of Northern Ontario”, Southern Journal of Anthropology 19 (1). 
History-based Explanatory Framework for Procreative Behaviour of Aboriginal People of Canada

Rogers, Edward S. 1972. "Leadership among the Indians of Eastern Sub arctic Canada", in Nagler Mark (ed.), Perspectives on the North American

Indians, McClelland and Stewart Limited, Toronto/Montreal

Romaniuk, A., 1974, "Modernization and fertility: The case of the James Bay Indians", Canadian Review of Sociology and Anthropology 11 (4): 344359.

Romaniuc, A. 1981. "Increase in natural fertility during the earlier stages of modernisation: Canadian Indian case study', Demography, 18(2):157-171.

Romaniuc, A. 1987. "Transition from traditional high to modern low fertility: Canadian Aboriginals", Canadian Studies in Population, 14(1): 69-88.

Romaniuc, A.. 1994. "Fertility in Canada: Retrospective and Prospective", in Frank Trovato and Carl F. Grindstaff (Eds), Perspectives on Canada's Population. Oxford: University Press.

Romaniuc A. 2000. "Aboriginal Population of Canada: Growth Dynamics under Conditions of Encounter of Civilisations", The Canadian Journal of Native Studies 20 (1): 96-137.

Romaniuc Anatole. 2003. "Fertility of a Community in Transition: the Case of James Bay Indians, Canada", The Canadian Journal of Natives Studies, XXIII, 2: 227-275.

Schaefer, Otto. 1975. "Food Resources and Changing Dietary Patterns of the Eskimo Child", in Nutrition of Indian and Eskimo Children. Report of the Second Canadian Ross Conference on Paediatric Research. Ed. by J. C. Haworth. Montreal, Quebec: Ross Laboratories. Pp. 4-11.

Shkilnyk, Anastasia M. 1985. A Poison Stronger Than Love -The Destruction of an Ojibwa Community. New Haven: Yale University Press.

Spady, D.W. 1982. Between Two Worlds. Edmonton: Boreal Institute for Northern Studies.

Stanley, George, F. G. 1960. The Birth of Western Canada-A History of the Riel Rebellion. Toronto: Toronto University Press. 
Anatole Romaniuk

Taylor, John. 1997. "The Contemporary Demography of Indigenous Australians", Journal of the Australian Population Association 14 (1): 77-114.

Trovato Frank and T.K. Burch. 1980. "Minority Group Status and Fertility in Canada", Canadian Ethnic Studies 12: 1-18.

Trovato, Frank. 1987. "A macro-sociological analysis of native Indian fertility in Canada: 1961, 1971 and 1981”, Social Forces 66(2): 463-485.

Zentner, Henry. 1972. "Reservation Social Structure and Anomie: A Case Study", in Nagler, Mark (Ed.), Perspectives on the North American Indians. McClelland and Stewart Limited, Toronto/Montreal. 